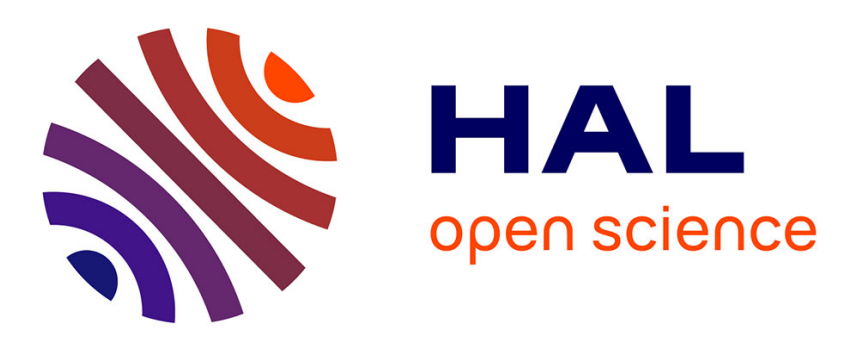

\title{
Long-term geometry of the geomagnetic field for the last five million years: An updated secular variation database
}

Xavier Quidelleur, Jean-Pierre Valet, Vincent Courtillot, Gauthier Hulot

\section{To cite this version:}

Xavier Quidelleur, Jean-Pierre Valet, Vincent Courtillot, Gauthier Hulot. Long-term geometry of the geomagnetic field for the last five million years: An updated secular variation database. Geophysical Research Letters, 2013, 21 (15), pp.1639-1642. 10.1029/94GL01105 . insu-01405155

\section{HAL Id: insu-01405155 \\ https://hal-insu.archives-ouvertes.fr/insu-01405155}

Submitted on 29 Nov 2016

HAL is a multi-disciplinary open access archive for the deposit and dissemination of scientific research documents, whether they are published or not. The documents may come from teaching and research institutions in France or abroad, or from public or private research centers.
L'archive ouverte pluridisciplinaire $\mathbf{H A L}$, est destinée au dépôt et à la diffusion de documents scientifiques de niveau recherche, publiés ou non, émanant des établissements d'enseignement et de recherche français ou étrangers, des laboratoires publics ou privés. 


\title{
Long-term geometry of the geomagnetic field for the last five million years: An updated secular variation database
}

\author{
Xavier Quidelleur, Jean-Pierre Valet, Vincent Courtillot and Gauthier Hulot \\ Institut de Physique du Globe, Paris, France
}

\begin{abstract}
Lee [1983] assembled more than two thousand paleomagnetic directional data from lava flows in 65 sampling sites with ages spanning the last 5 million years. Constable [1992] recently suggested that the virtual geomagnetic poles (VGP) derived from this data base have been preferentially located within two antipodal bands of longitude. We have reanalyzed and updated the Lee data base, yielding a total of 3179 data from 86 distinct sites. Neither the total data set, nor various subsets of the data unambiguously show any large and clear maxima in the longitude distribution of VGPs. The shape of the common site longitude distribution is far more striking with a pronounced (and robust) minimum close to the common site longitude and secondary maxima about $120^{\circ}$ away from it. The former (first order) feature is equivalent to the far-sided effect discovered by Wilson [1970] and corresponds to a persistent axial quadrupole amounting to about $5 \%$ of the axial dipole, as previously found by several authors. The latter (second order) feature could correspond to the VGP biasing effect described by Egbert [1992] although its observed amplitude appears larger than predicted. Part of this effect (an asymmetry in the maxima) may also correspond to Wilson's [1971] right-handed effect. Given only a small axial quadrupolar component and the very uneven actual site distribution, the expected longitude distribution of VGPs can be calculated: this is found to be in good agreement with the paleomagnetic observations (i.e. rather flat with a moderate maximum near $120^{\circ} \mathrm{E}$ ). This study emphasizes problems related to the unsatisfactory distribution of sites. The amplitude and significance of other terms, beyond the dominant axial dipole and significant axial quadrupole contribution, remain to be assessed.
\end{abstract}

\section{Introduction}

Developments in paleomagnetism and plate tectonics, including attempts to refine a global geomagnetic reversal time scale, have led to large amounts of paleomagnetic sampling of lava flows, particularly since the late '60s. In 1983, Lee assembled a base comprising most directional data covering the last 5 million years and published up to 1977. The data base was not formally published or widely circulated but it has been at the basis of most statistical analyses of the long-term time-averaged geomagnetic field, beginning with Merrill and McElhinny [1983]. The same data base has recently led Constable [1992] to suggest that the virtual geomagnetic poles (VGP) derived from the individual directional data have been preferentially located within two antipodal bands of longitude during the last 5 million years. Constable [1992] linked this observation with a similar observation for the transitional paths of VGPs for the past few reversals [e.g. Clement, 1991; Tric et al., 1991] and concluded that the time-averaged field contains persistent non-zonal contributions. Valet et al. [1992] have since challenged the statistical significance of the reversal data (see also Prévot and Camps, 1993) and shown that an equally (or more) significant pattern for transitional paths is that they

Copyright 1994 by the American Geophysical Union. tend to be located $90^{\circ}$ away from the observation site, a phenomenon which could in part be due to a statistical biasing effect [Egbert, 1992]. McFadden et al. [1993] have since confirmed both the significance of the preferential bands of longitude and of the " $90^{\circ}$ away from the site" shift, arguing that the latter feature may be the significant one.

This led us to reanalyse and update the Lee [1983] data base to see if the features uncovered by Constable [1992] were indeed robust. The Lee data base comprised a total of 2244 data (i.e. readings from individual lava flows) coming from 65 distinct sampling sites. In her synthesis, Lee rejected data when the pole appeared to be transitional (VGP latitude between $45^{\circ} \mathrm{N}$ and $45^{\circ} \mathrm{S}$ ), when the $95 \%$ confidence cone had a radius in excess of $20^{\circ}$ and when individual directions were calculated from a single sample. For each study, there had to be at least 5 flows of a given polarity (normal or reversed) to generate average data, and finally the latitudes of VGPs for each polarity, once averaged, had to be at least $60^{\circ}$. Because detailed descriptions were lacking, no criterion based on rock magnetic properties could be applied. We have reviewed the data base and added 815 data from 14 sites in studies published since 1980, and 120 data from 7 sites corresponding to earlier publications. As a result, the total data base now comprises 3179 data from 86 distinct sites. It is available from the authors, complete with references, on ftp.

\section{Results}

The distribution of sampled sites for which data have been retained is shown in Figure 1. We note that several areas (the Atlantic Ocean, South America and the eastern Indian Ocean in the Southern hemisphere, and Eastern North America, the western Atlantic Ocean and continental Asia in the Northern hemisphere) are essentially devoid of data. On the other hand, large amounts of data come from a restricted number of sites, particularly hot spot volcanoes such as Hawaii, Iceland, and the south-western Indian Ocean. In what follows, we have analyzed and displayed for several subsets of the data base the longitude distribution of sites, of VGPs and also the differences between VGP and site longitudes, that is the "common site longitude" first introduced by Wilson [1971]. Figure 2 (c, $d$ and e) displays these three distributions for the total updated database.

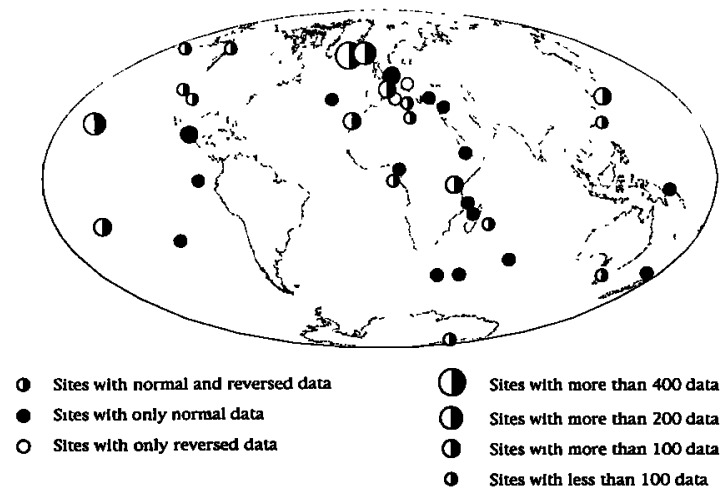

Figure 1: Geographic distribution of the sampling areas. In several cases distinct sampling sites are included within the same area. 
a)

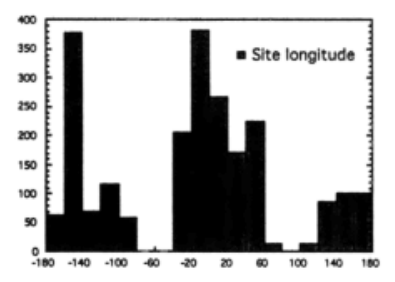

b)

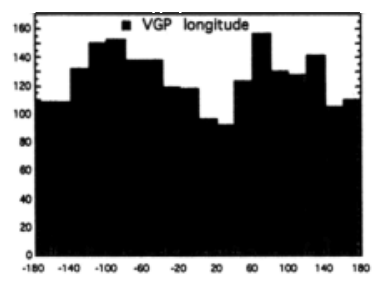

c)

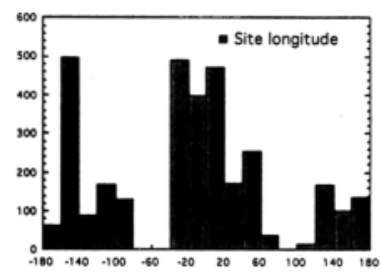

d)

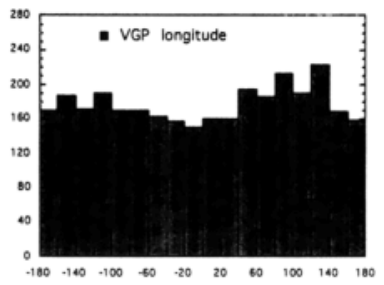

e)

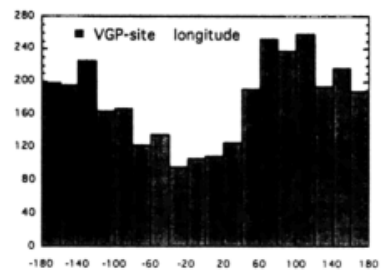

Figure 2: a) and b) Histograms showing respectively the distributions of the site longitudes (20 ${ }^{\circ}$ bins) and VGP longitudes based on the Lee [1983] database, from Constable [1992]. c), d) and e) Histograms showing the distributions of site, VGP, and VGP-site longitudes, from the total updated database (3179 data), this paper.

Comparing the VGP longitude distribution published by Constable [1992] based on the original Lee database (Figure $2 \mathrm{~b}$ ) and the distribution obtained from our total updated database (Figure $2 \mathrm{~d}$ ), the first observation is that the strong clustering of VGPs in preferred longitude bands does not seem to be confirmed. Although the distribution of added VGPs seems to be more uniform (though noisy), maxima and minima do exist but they are somewhat different from those observed in Figure $2 \mathrm{~b}$. We note that a few sites from the Lee database contribute comparatively large numbers of very confined data. More precisely, the Fisher precision parameter $\mathbf{K}$ for individual sites ranges from about 10 to 650 . The distribution of $K$ displays a bell-like shape, with a very long tail towards the high values and a gap between 65 and 85 . Eleven records from eight distinct sites appear to be outliers, with $K$ values larger than 85 , probably reflecting lack of averaging of secular variation due to a very short time sampling. We have removed the corresponding 232 data points ( 12 normal data from the Indian Ocean, 23 from the Western Pacific, 23 from Yellowstone, 9 from Hawaii, 42 reversed data from Kauai, 26 normal and reversed data from Ethiopia, 18 from Niihau and 79 from Norfolk Island). The resulting updated database is that used in the present study; it includes
2947 independent volcanic recordings of the geomagnetic field direction from 79 sites (Table 1). The corresponding distributions are displayed in Figure 3 a-c (both polarities), d-f (normal) and g-i (reversed).

We first observe that the two clear maxima of the VGP longitude distribution found by Constable [1992] near $90^{\circ} \mathrm{W}$ and $90^{\circ} \mathrm{E}$ (Figure 2 b), which had already diminished significantly in Figure $\mathbf{2} \mathbf{d}$ are essentially absent. A moderate maximum is observed near $130^{\circ} \mathrm{E}$ in what appears to be a rather uniform distribution. Similar situations are observed when only normal or reversed flows are included (compare Figure $3 \mathrm{~b}, e$ and $h$ ). The overall average VGPs for these three subsets are within 0.9 to $2.4^{\circ}$ from the geographic pole although their $95 \%$ confidence intervals fail to include it by 0.3 to $1.3^{\circ}$ (Table 2).

The shape of the common site longitude distribution (Figure $2 \mathrm{e}$, Figure $3 \mathrm{c}, \mathrm{f}$ and $\mathrm{i}$ ) is far more striking with a pronounced minimum close to the site longitude. This feature appears to be quite robust and was found in the analyses of all subsets of data (e.g. considering only data from the Brunhes Chron, or removing Icelandic or Hawaiian data from the complete database, or even displaying results from very limited areas such as Iceland or Hawaii alone). We have also tested
Normal \& Reversed

a)

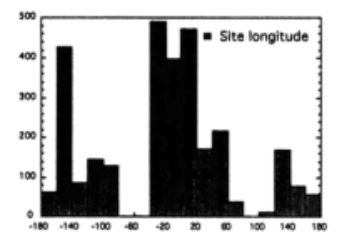

b)

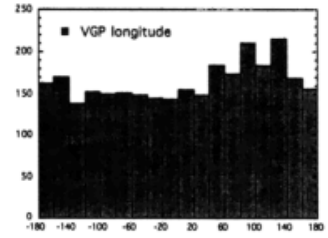

c)

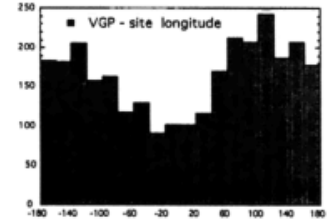

d)

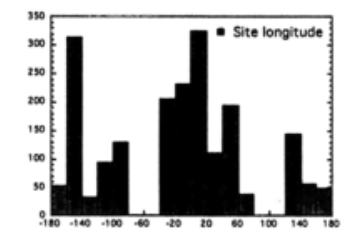

e)

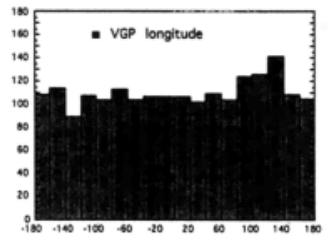

f)

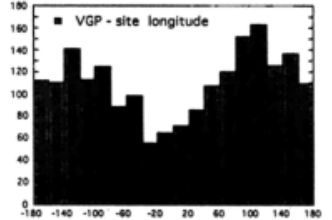

Reversed

g)

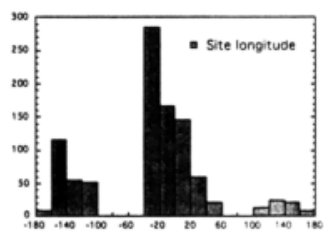

h)

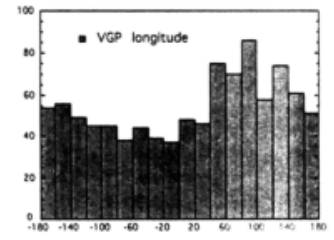

1)

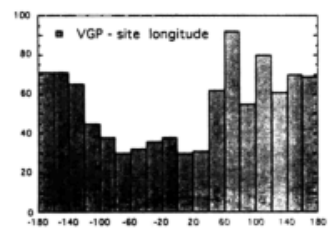

Figure 3: a), b) and c) Histograms of the site, VGP and VGP-site longitude distributions for the combined normal and reversed polarity data (2947 data). d), e) and f) same for normal polarity data (1976 data). g), h) and i) same for reversed polarity data ( 971 data). All data from the edited and updated data base described in this paper. 
Table 1. Characteristics of Data Bases

\begin{tabular}{lccc}
\hline Numbers of & Lee database & $\begin{array}{c}\text { Lee corrected } \\
\text { database }\end{array}$ & $\begin{array}{c}\text { Updated } \\
\text { database }\end{array}$ \\
\hline $\begin{array}{l}\text { Studies } \\
\text { Sampling sites }\end{array}$ & 52 & 45 & 66 \\
& 65 & 58 & 79 \\
$\begin{array}{l}\text { Sampling areas } \\
\text { (see Figure 1) }\end{array}$ & 34 & 33 & 37 \\
$\begin{array}{l}\text { All data } \\
\text { Normal data }\end{array}$ & 2244 & 2012 & 2947 \\
Reversed data & 1454 & 1328 & 1976 \\
\hline
\end{tabular}

Table 2. Mean pole positions

\begin{tabular}{lccc}
\hline Polarity & Lee database & $\begin{array}{c}\text { Lee corrected } \\
\text { database }\end{array}$ & $\begin{array}{c}\text { Updated } \\
\text { database }\end{array}$ \\
\hline & \multicolumn{3}{c}{ Overall mean poles } \\
Normal and & $88.9 ; 149.1$ & $88.4 ; 124.4$ & $88.7 ; 105.5$ \\
Reversed & 0.6 & 0.6 & 0.6 \\
Normal & $89.2 ; 152.9$ & $89.0 ; 130.8$ & $89.1 ; 85.0$ \\
& 0.7 & 0.8 & 0.6 \\
Reversed & $88.4 ; 145.4$ & $87.2 ; 119.9$ & $87.6 ; 120.7$ \\
& 1.1 & 1.2 & 1.1 \\
Normal and & $86.5 ; 138.2$ & $86.5 ; 145.1$ & $87.4 ; 146.0$ \\
Reversed & 0.6 & 0.6 & 0.6 \\
Normal & $87.4 ; 143.8$ & 87.21151 .0 & $87.9 ; 146.3$ \\
& 0.7 & 0.7 & 0.6 \\
Reversed & $84.9 ; 133.1$ & $85.0 ; 138.5$ & $86.3 ; 145.6$ \\
& 1.1 & 1.1 & 1.0 \\
\hline
\end{tabular}

Latitude, longitude and $\alpha_{95}$ in degrees.

the stability of this observation with a normalization of the site distribution using a random selection of no more than 50 data per band of site longitudes.

This first-order feature is simply a consequence of the far-sided effect discovered by Wilson [1970, 1971] and further studied by McElhinny [1973], Wilson and McElhinny [1974] and more recently Merrill and McElhinny [1983]. Following these authors, another representation of the effect is shown in Figure $4 \mathrm{a}$ and $\mathrm{b}$ where average poles are calculated for each of nine sectors of longitude. Figure $4 \mathrm{c}$ displays the mean normal and reversed poles in common site longitude and polar projection (which can be compared to Figure 6.2 of Merrill and McElhinny, 1983). The pole always tends to plot too far from the geographic pole along the site meridian. This effect has been widely discussed and is equivalent to that due to a northward-displaced dipole or to a geocentric axial quadrupole $\left(g_{2}^{0}\right)$. It could be attributed to shallowing of the inclination in the remanence acquisition process, shape anisotropy in lava flows or incomplete magnetic cleaning. The reasons invoked by Merrill and McElhinny [1983, p. 185] to discard these still apply. In the same vein, tectonic displacements or inadequate dip flow corrections should average out in such a large data base. The data displayed in Figures 2 and 3 are therefore in agreement with previous studies which conclude that there is a small but significant axial quadrupole, on the order of $5 \%$ of $g_{1}^{0}$ [e.g. Coupland and Van der Voo, 1980; Merrill and McElhinny, 1983 ; Constable and Parker, 1988; Schneider and Kent, 1990].

Figure $4 \mathrm{c}$ also confirms the slight but significant polarity asymmetry between the normal and reversed states discussed for instance by Merrill and McElhinny [1983] and observed in deep-sea sediments by Schneider and Kent [1990]. To our knowledge there is no generally accepted interpretation for this observation.

A second order feature is the presence of two maxima near $110^{\circ}$ and $-130^{\circ}$, hence of a secondary minimum close to $180^{\circ}$ (Figures $2 \mathrm{e}$ a)

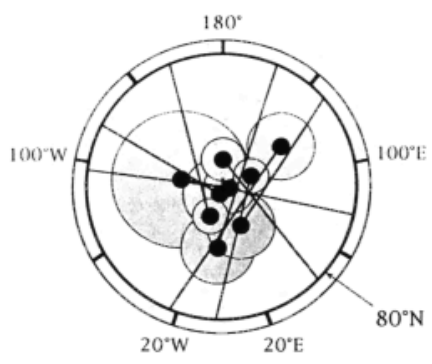

b) $\quad$ Reversed mean VGPs
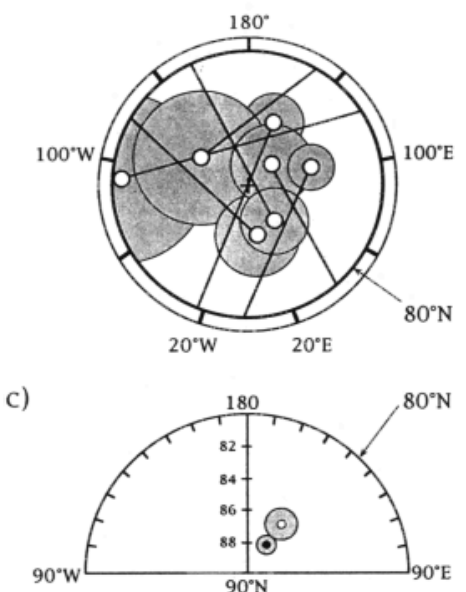

Figure 4: a) Polar stereographic projection (latitudes higher than $80^{\circ} \mathrm{N}$ ) of the mean poles averaged within $40^{\circ}$-wide sectors of site longitude considering only normal polarity data from the edited and updated data base (1976 data). The intersections of the sphere with the $95 \%$ confidence cones are shown in grey. b) Same as a) considering the reversed polarity data only (971 data). Note that no reversed polarity data have been sampled within two sectors of longitude. c) Polar stereographic projection of average poles in common site longitude, with the $95 \%$ confidence cone associated, for the normal and reversed polarities (closed and open circle, respectively) from the edited and updated data base (see Figure $3 \mathrm{f}$ and $\mathrm{i}$, and values in Table 2).

and $3 \mathrm{c}, \mathrm{f}$ and $\mathrm{i}$ ). This could result from the VGP biasing described by Egbert [1992]. In order to test this hypothesis, we have tried to estimate its effect in conjunction with the very uneven distribution of sampling sites (with in particular no observations, or almost no observations, in two $40^{\circ}$-wide bands of VGP longitudes, see Figures 2 a, c and 3 a, d, g). We have used the statistical geomagnetic field model of Constable and Parker [1988], assuming an axial quadrupole amounting to $5 \%$ of the axial dipole contribution, to compute a hundred times 2947 synthetic data for the sites associated with the 2947 real observations. The mean VGP longitude and VGP-site longitude distributions are shown in Figure $5 \mathrm{a}$ and $\mathrm{b}$, the standard deviation $(\sigma)$ being given for each band of longitude (light shading). The VGP longitude distribution (Figure 5a) is rather flat, not unlike the observed distribution obtained from the database (Figure $3 \mathrm{~b}, \mathrm{e}$ and h). The VGP-site longitude distribution also shows the same characteristics as found from the updated database (Figure $3 \mathrm{c}$ ), with a pronounced minimum around the site longitude induced by the axial quadrupolar term in the model. The Egbert [1992] effect near $\pm 90^{\circ}$ is present in this figure by construction, although its amplitude is apparently too small to be seen clearly. Given the calculated standard deviation on the model and the expected and unavoidable noise in real data, the distribution of Figure $5 \mathrm{~b}$ is compatible with the distribution in Figure $3 \mathrm{c}$, except possibly for bands located around $70^{\circ}$ and $110^{\circ} \mathrm{E}$ : for these two bins, the counts obtained from data (Figure $3 \mathrm{c}$ ) are 


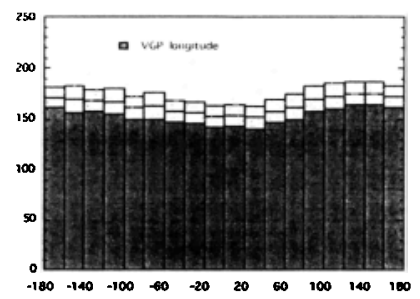

b)

Calculated VGP-site longitude discribution

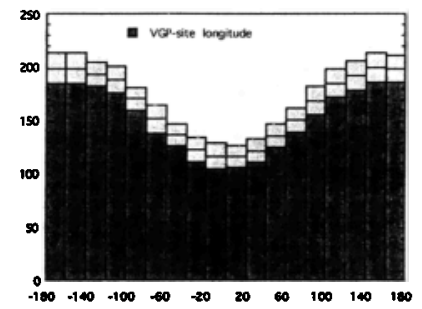

Figure 5: a) Mean VGP longitude distribution and standard deviations (light shading) obtained from 100 iterations of the statistical model of Constable and Parker [1988] (with an axial quadrupole amounting to $5 \%$ of the axial dipole contribution), sampled by the site distribution of the global edited and updated data base ( 2947 data). b) Same as a) for VGP-site longitude distribution.

outside of a $3 \sigma$ interval about the mean value. This observation, if significant, may be related to the right-handed effect, also discovered by Wilson $[1971 ; 1972]$ and present in Figure 4.

\section{Conclusions}

The above analysis of an updated database of some 3000 paleomagnetic directions from volcanic flows spanning the last 5 million years does not confirm the existence of preferential bands of longitude for VGPs suggested by Constable [1992]. The VGP distribution is rather uniform although it does vary when various subsets of data are used because of the very uneven distribution of observation sites. When displayed in common site longitude, the distributions appear to be much more robust and to display a pronounced minimum centered on the site longitude. This effect simply corresponds to the well known far-sidedness discovered by Wilson [1970; 1971]. The statistical geomagnetic field model of Constable and Parker [1988], which includes a significant axial quadrupole, combined with the uneven site distribution reproduces this feature. A departure from the model is the presence of secondary maxima near $+110^{\circ}$ and $-130^{\circ}$ away from the site longitude. Such bias cannot be accounted for solely by the mathematical transformation from paleomagnetic directions to VGPs [Egbert, 1992]. The $+110^{\circ}$ maximum, which is the most significant (Figure $3 \mathrm{c}$ ) probably reflects the right-handed effect introduced by Wilson [1971] and subsequently noticed by several authors [Wilson, 1971; 1972; Merrill and McElhinny, 1983; Constable and Parker, 1988]. It could result from the combination of other long-term spherical harmonics with the present site distribution (work in progress). As this paper was in review C. Johnson and C. Constable (personal communication, 1993) kindly provided us with a manuscript submitted to the Philosophical Transactions of the Royal Society of London, presenting another updated version of the Lee database. Although their data sources and selection criteria are somewhat different from ours, resulting in a final data set with less records (2187) from more locations (104), they come to results which are essentially in agreement with ours, emphasizing the role of data distribution and quality. In conclusion, largely due to the uneven (and unsatisfactory) site distribution, it seems that all that can be extracted (to first order) from the large paleomagnetic database is the dominant axial dipolar geometry of the long-term average of the geomagnetic field $\left(g_{1}^{0}\right)$, with the addition of a small but significant axial quadrupole $\left(g_{2}^{0}\right)$. There is as yet no definite evidence for first degree non-zonal contributions in the distribution of VGP longitudes.

Acknowledgments. We thank C. Johnson and C. Constable for providing us with the complete Lee data base and for helpful discussions. The data can be accessed through "anonymous ftp geospl ipgp.jussieu.fr"; use mail address as password and type "cd paleo". IPGP contribution NS 1290.

\section{References}

Clement, B.M., Geographical distribution of transitional VGPs: evidence for non-zonal equatorial symmetry during the Matuyama-Brunhes geomagnetic reversal, Earth planet. Sci. Lett., 104, 48-58, 1991.

Constable, C.G., Link between geomagnetic reversal paths and secular variation of the field over the past $5 \mathrm{Myr}$, Nature, 358, 230-233, 1992.

Constable, C.G. and R.L. Parker, Statistics of the geomagnetic secular variation for the past 5 m.y., J. Geophys. Res., 93, 11569-11581, 1988.

Coupland, D.H. and R. Van der Voo, Long-term nondipole components in the geomagnetic field during the last 130 M.Y., J. Geophys. Res., 85, 3529 $3548,1980$.

Egbert, G.D., Sampling bias in VGP longitudes, Geophys. Res. Lett., 23, 23532356, 1992.

Lee, S., A Study of the Time-averaged Paleomagnetic Field for the Last 195 Million Years, Ph.D. thesis, Australian Natl. Univ., Canberra, 1983.

McElhinny, M.W., Palaeomagnetism and Plate Tectonics, Cambridge University Press, Cambridge, 358 pp., 1973.

McFadden, P.L., C.E. Barton, and R.T. Merrill, Do virtual geomagnetic poles follow preferred paths during geomagnetic reversals?, Nature, 361, 342344, 1993.

Merrill, R.T. and M.W. McElhinny, The Earth's Magnetic Field, Academic Press, London, 401 pp., 1983.

Prévot, M. and P. Camps, Absence of longitudinal confinement of poles in volcanic records of geomagnetic reversals, Nature, 366, 53-57, 1993.

Schneider, D.A. and D.V. Kent, The time-averaged paleomagnetic field, Rev. Geophys., 28, 71-96, 1990.

Tric, E., C. Laj, C. Jehanno, J.-P. Valet, C. Kissel, A. Mazaud, and S. Iaccarino, High resolution record of the upper Olduvai transition from Po Valley (Italy) sediments: support for dipolar transition geometry?, Phys. Earth planet. Inter., 65, 319-336, 1991.

Valet, J.-P., P. Tucholka, V. Courtillot, and L. Meynadier, Paleomagnetic constraints on the geometry of the geomagnetic field during reversals, Nature, 356, 400-407, 1992.

Wilson, R.L., Permanent aspects of the Earth's non-dipole magnetic field over upper Tertiary times, Geophys. J. R. astron. Soc., 19, 417-437, 1970.

Wilson, R.L., Dipole offset - the time-averaged palaeomagnetic field over the past 25 million years, Geophys. J. R. astron. Soc., 22, 491-504, 1971.

Wilson, R.L., Palaeomagnetic differences between normal and reversed field sources, and the problem of far-sided and right-handed pole positions, Geophys. J. R. astron. Soc., 28, 295-304, 1972.

Wilson, R.L. and M.W. McElhinny, Investigation of the large scale palaeomagnetic field over the past 25 million years. Eastward shift of the Icelandic ridge, Geophys. J. R. astron. Soc., 39, 570-586, 1974.

V. Courtillot, Laboratoire de Paléomagnétisme, Département de Géomagnétisme et Paléomagnétisme, CNRS URA 729, Institut de Physique du Globe de Paris, 4, Place Jussieu, 75252 Paris Cedex 05, France. (e-mail: courtillot@ipgp.jussieu.fr)

G. Hulot, Laboratoire de Géomagnétisme, Département de Géomagnétisme et Paléomagnétisme, CNRS URA 729, Institut de Physique du Globe de Parns, 4, Place Jussieu, 75252 Paris Cedex 05, France. (e-mail: hulot @ipgp.jussieu.fr)

$X$. Quidelleur, Laboratoire de Paléomagnétisme, Département de Géomagnétisme et Paléomagnétisme, CNRS URA 729, Institut de Physique du Globe de Paris, 4, Place Jussieu, 75252 Paris Cedex 05, France. (e-mail: quidel@ipgp.jussieu.fr)

J.-P. Valet, Laboratoire de Paléomagnétisme, Département de Géomagnétisme et Paléomagnétisme, CNRS URA 729, Institut de Physique du Globe de Paris, 4, Place Jussieu, 75252 Paris Cedex 05, France. (e-mail: valet@ipgp.jussieu.fr)

(Received October 7, 1993; revised December 1, 1993; accepted December 3, 1993.) 